\title{
COMPARISON OF DIDACTIC LECTURES AND CASE-BASED LEARNING IN AN UNDERGRADUATE BIOCHEMISTRY COURSE AT RAK MEDICAL AND HEALTH SCIENCES UNIVERSITY, UAE
}

\author{
Jeevan K. Shetty¹, Gulam Saidunnisa Begum², Manjunatha B. K. Goud³, Beenish Zaki ${ }^{4}$ \\ ${ }_{1}^{1}$ Associate Professor, Department of Biochemistry, Ras Al-Khaimah Medical and Health Sciences University, Ras Al-Khaimah. \\ ${ }^{2}$ Chairperson and Professor, Department of Biochemistry, Ras Al-Khaimah Medical and Health Sciences University, Ras Al-Khaimah. \\ ${ }_{3}^{3}$ Assistant Professor, Department of Biochemistry, Ras Al-Khaimah Medical and Health Sciences University, Ras Al-Khaimah. \\ ${ }_{4}^{4}$ Former Senior Instructor, Department of Biochemistry, Ras Al-Khaimah Medical and Health Sciences University, Ras Al-Khaimah.
}

\section{ABSTRACT}

Biochemistry is one of the basic medical subjects in the first year and is one of the foundation sciences for the medical curriculum. Knowledge of Biochemistry is extensively related in the context of clinical disease during medical practice, it needs to be taught and learned efficiently by medical graduates.

\section{OBJECTIVES}

This study was conducted to analyse the perceptions of first year medical students about the didactic lecture and case-based learning, teaching learning methodology in Biochemistry course.

\section{MATERIALS AND METHODS}

This cross-sectional study was conducted at RAK College of Medical Sciences (RAKCOMS). About ( $\mathrm{n}=126$ ) first year medical students were administered with 14-item questionnaire to determine their perceptions of students on didactic lecture and casebased learning. Data was analysed using descriptive analysis on SPSS 16.

\section{RESULTS}

As per our study majority of the students expressed their satisfaction that CBL was a useful teaching methodology in understanding the concepts in Biochemistry. Majority felt this method motivated them to critically think in filling the learning gaps and building the concepts. They also had an opinion that this method facilitated interaction between staff and students from different cultures and backgrounds, which helped them developing their inter- and intrapersonal relations.

\section{CONCLUSION}

In conclusion, case-based learning can be good substitute for teaching Biochemistry for first year MBBS students, which can be used alone or in combination with didactic lecture to make the Biochemistry more interesting and understandable to MBBS students. We implemented CBL method of teaching with encouraging and positive results.

\section{KEYWORDS}

Didactic Lecture, Case-Based Learning, Biochemistry, MBBS.

HOW TO CITE THIS ARTICLE: Shetty JK, Begum S, Goud MBK, et al. Comparison of didactic lectures and case-based learning in an undergraduate biochemistry course at RAK Medical and Health Sciences University, UAE. J. Evolution Med. Dent. Sci. 2016;5(50): 3212-3216, DOI: $10.14260 /$ jemds/2016/745

\section{INTRODUCTION}

Today's class lecture galleries are filled with students of diverse backgrounds, cultures and languages, hence educationists recommend different teaching styles to be adapted in order to reach each student's learning style in the classroom.

Large group pedagogy teaching has always been the most popular and traditional way of teaching from past decades. It is one of the most convenient and economical way to transfer knowledge from content expert to the learner. Academicians always encourage the role of active learning in this method.

Financial or Other, Competing Interest: None.

Submission 02-05-2016, Peer Review 31-05-2016,

Acceptance 06-06-2016, Published 23-06-2016.

Corresponding Author:

Dr. Gulam Saidunnisa Begum,

Chairperson and Professor of Biochemistry,

Ras-Al-Khaimah Medical and Health Sciences University,

Room Number and Extension: 251,

Po. Box: 11172 ,

Ras-Al-Khaimah, UAE.

E-mail: saidunnisa@rakmhsu.ac.ae

DOI: 10.14260/jemds/2016/745
"Tell me and I forget, teach me and I may remember, involve me and I learn." Benjamin Franklin.

In this context, medical schools have been changing their educational programs and teaching strategies to ensure that the students had active responsibility for their learning process and that they were prepared for life-long, selfdirected learning.[1]

The effort towards developing active learning was based on the concern that students memorized facts ("Rote learning") instead of understanding and applying the concepts ("Meaningful learning").[2] Meaningful learning involves the acquisition of "useful" knowledge because: It is stored in such a way that it can be accessed from different starting points, well integrated with previous knowledge and accompanied by the building of multiple representations [Mental models], which are connected to other models for many other phenomena. [3]

Biochemistry is one of the basic medical science subjects in the first year and is one of the foundation sciences for the medical curriculum.

It needs to be taught and learned efficiently, so as to be placed in the context of a clinical disease when the medical 
students graduate and practice in the community.

At RAK College of Medical Sciences (RAKCOMS) in teaching Biochemistry we use multiple teaching- learning methodology tools like didactic lecture, Case-Based Learning (CBL), Problem-Based Learning (PBL), seminars and small group discussions. The main objective of these activities is to provide students with a more interesting and practical approach to learn Biochemistry, such as the application of theoretical knowledge to real situations (Diseases, experiments, media information and scientific discoveries). ${ }^{[4]}$

Didactic lectures are pedagogical method that conveys the basic Biochemical concepts and their clinical relevance. There is little opportunity for students to clarify their doubts and reinforce the concepts they learn during the didactic lectures. As a result, students find it difficult to relate clinical problems with Biochemical concepts. Moreover, students find it difficult to listen to their teachers continuously for many hours without any active participation.

Case-Based Learning (CBL) is a pedagogical method that uses case studies as active learning tools is an established method in undergraduate medical education throughout the world and aims to develop reasoning skills based on clinical case scenarios, which allow the medical student to learn the basic medical science subjects in context of a medical problem.[5]

Qualitative studies of case-based learning methods suggest that students comprehend concepts, retain content longer and achieve critical thinking and real-world problem solving skills.[6] However, quantitative and summative data have not been sufficiently investigated, especially in the medical subject Biochemistry.[7] This study was conducted to analyse the perceptions of first year medical students about the didactic and Case-Based Learning (CBL) methodologies.

\section{MATERIALS AND METHODS}

This study was conducted at RAK College of Medical Sciences, (RAKCOMS). Ras-Al-Khaimah, UAE. A total of 126 first year MBBS students were included in this study. Students were from different ethnicity, cultures and backgrounds (Asian, European and Western) and also underwent their education in different curriculum (CBSE, IB, Arabic Board) during their $10+2$ board exams. Eligibility criteria is TOEFL pass with score of 400 and above. Medium of instruction for all the students is English. They were taught medical subjects Anatomy, Biochemistry, physiology along with mathematics, health science communication in English and Arabic. They have three hours of theory classes and one practical session per week in Biochemistry.

Some of these classes were taught as didactic lecture and some topics as case-based learning along with other teaching modalities. Detailed list of topics covered in the CBL and didactic lecture is given in the Table 2. Didactic lectures were conducted traditionally, where teacher explains the topic with help of teaching aids like power point presentations, white board.

\section{Example of Process of CBL Conducted at RAK College of} Medical Sciences, (RAKCOMS) Biochemistry Department

Step-1: Relevant case to the topic will be projected and student will be asked to read and understand.

Step-2: This is usually followed by playing of videos where ever needed, which will complement to the case.

Step-3: Discussion of the Biochemical basis of the case will be done in the class using white board and power point presentation.

Step-4: Last session students will be divided into small groups and tutorial activity will be given to fill the learning gaps through collaborative work. Appendix I gives the example of a case used in the case-based learning.

After the completion of the session, students were administered with 14 items of questionnaire to know the perception of students on case-based learning and didactic lecture. Sample of the questionnaire along with responses asked for is given in Table I. Ethical approval obtained from Institutional Research Committee before commencing of the study.

\section{RESULTS}

As per our study, $49 \%$ of students have expressed their satisfaction that CBL was a useful teaching methodology in understanding the concepts in Biochemistry.

Around $63 \%$ of them felt this method motivated them to critically think and $51 \%$ of them felt it helped them in filling the learning gaps and $44 \%$ felt it was useful in building the concepts. About $49 \%$ of them also had an opinion that this method facilitated interaction between staff and students from different cultures and backgrounds, which helped them developing their inter- and intra-personal relations. (Table 1 and Figure 1).

Majority 85\% felt cases used during CBL were interesting and relevant to first year. (Table 1 and Figure 2) 54\% were of the opinion this method was useful and it should be continued for future teaching Biochemistry topics as well other subjects should be also taught in similar way; $86 \%$ expressed that there should be a mixture of didactic lectures and case-based learning sessions for a better understanding of a particular system and associated clinical conditions. Additional comments are represented in Table 1.

\begin{tabular}{|c|c|c|c|c|}
\hline Question & $\begin{array}{l}\text { DL } \\
(\%)\end{array}$ & $\begin{array}{l}\text { CBL } \\
(\%)\end{array}$ & $\begin{array}{c}\text { Both } \\
\text { DL \& } \\
\text { CBL } \\
(\%)\end{array}$ & $\begin{array}{c}\text { Both } \\
\text { not } \\
\text { useful } \\
(\%)\end{array}$ \\
\hline 1. Which type of teaching methodology is useful in understanding Biochemistry topics? & 7 & 49 & 42 & 2 \\
\hline $\begin{array}{l}\text { 2. Which type of teaching methodology was helpful in filling the learning gaps in } \\
\text { Biochemistry course? }\end{array}$ & 15 & 51 & 30 & 4 \\
\hline $\begin{array}{l}\text { 3. Which type of teaching methodology was helpful to build the concepts of } \\
\text { Biochemistry subject? }\end{array}$ & 22 & 44 & 25 & 4 \\
\hline $\begin{array}{l}\text { 4. Which type of teaching methodology was useful in terms of group discussion and } \\
\text { critical thinking? }\end{array}$ & 11 & 63 & 25 & 1 \\
\hline 5. Which methodology facilitated interaction between staff and students? & 14 & 49 & 30 & 7 \\
\hline
\end{tabular}




\begin{tabular}{|c|c|c|c|c|}
\hline $\begin{array}{l}\text { 6. Which teaching methodology you would suggest to be continued for future teaching } \\
\text { sessions? }\end{array}$ & 9 & 54 & 36 & 1 \\
\hline $\begin{array}{l}\text { 7. Do you feel which one of the following teaching methodologies will facilitate to work } \\
\text { well with people from other cultures and backgrounds? }\end{array}$ & 13 & 52 & 26 & 9 \\
\hline 8. Which methodology you prefer for learning other subjects? & 26 & 38 & 32 & 4 \\
\hline \multirow{2}{*}{ 9. Do you feel case presented during CBL were interesting? } & \multicolumn{2}{|c|}{ Yes } & \multicolumn{2}{|c|}{ No } \\
\hline & \multicolumn{2}{|c|}{86.51} & \multicolumn{2}{|c|}{13.49} \\
\hline \multirow{2}{*}{ 10. Do you feel cases presented were relevant to first year? } & \multicolumn{2}{|c|}{ Yes } & \multicolumn{2}{|c|}{ No } \\
\hline & \multicolumn{2}{|c|}{85.71} & \multicolumn{2}{|c|}{14.29} \\
\hline \multirow{2}{*}{$\begin{array}{l}\text { 11. Do you feel case-based learning approach is very motivating to learn Biochemistry } \\
\text { than didactic lecture? }\end{array}$} & \multicolumn{2}{|c|}{ Yes } & \multicolumn{2}{|c|}{ No } \\
\hline & \multicolumn{2}{|c|}{84.92} & \multicolumn{2}{|c|}{15.08} \\
\hline \multirow{2}{*}{ 12. Do you feel case-based learning makes learning more effective by working in groups? } & \multicolumn{2}{|c|}{ Yes } & \multicolumn{2}{|c|}{ No } \\
\hline & \multicolumn{2}{|c|}{77.7} & \multicolumn{2}{|c|}{22.3} \\
\hline \multirow{2}{*}{$\begin{array}{l}\text { 13. Do you feel that there should be a mixture of didactic lectures and case-based } \\
\text { learning sessions for a better understanding of a particular system and associated } \\
\text { clinical conditions? }\end{array}$} & \multicolumn{2}{|c|}{ Yes } & \multicolumn{2}{|c|}{ No } \\
\hline & \multicolumn{2}{|c|}{86.51} & \multicolumn{2}{|c|}{13.49} \\
\hline \multicolumn{5}{|l|}{ Do you wish to make any additional comments? } \\
\hline \multicolumn{5}{|c|}{$\begin{array}{l}\text { Following are the additional comments from the participants which were positive. Some of them were quite useful suggestions } \\
\text { regarding improvement in various facets. }\end{array}$} \\
\hline \multicolumn{5}{|c|}{$\begin{array}{l}\text { 1. Didactic or CBL depends on the topic; I believe for more complicated topic, I had to prefer CBL. But for a simple one didactic } \\
\text { lecture is fine. }\end{array}$} \\
\hline \multicolumn{5}{|l|}{ 2. More cases may be provided } \\
\hline \multicolumn{5}{|l|}{ 3. Both methods are nice } \\
\hline \multicolumn{5}{|l|}{ 4. Mix of both extremely effective } \\
\hline \multicolumn{5}{|l|}{ 5. We would mostly like case-based learning and little of didactic lecture } \\
\hline 6. Case-based learning makes the session interesting & & & & \\
\hline 7. More cases with relating videos are useful & & & & \\
\hline 8. Short crisp lectures with cases & & & & \\
\hline 9. Case-based learning allows us to apply the knowledge and concepts taught to the clin & sp & & & \\
\hline 10. All lectures are ideally made as CBL based. & & & & \\
\hline 11. CBL is more practical based & & & & \\
\hline $\begin{array}{l}\text { 12. Both are efficient, whereas didactic has the advantage of having simple and short yet } \\
\text { would enhance the learning. However, case-based is very thorough and knowledgeab }\end{array}$ & & & & \\
\hline 13. CBL will help us to understand and to implement our Biochemistry knowledge of Bio & mist & dail & & \\
\hline 14. Both methodologies are equally good in their & & & & \\
\hline
\end{tabular}

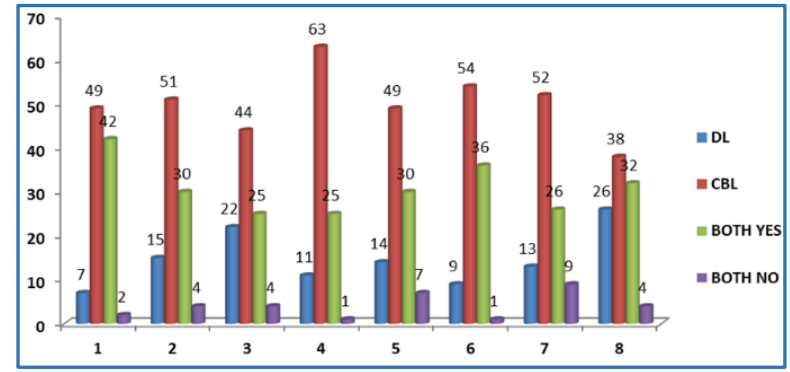

Fig. 1: Showing the Results of Students' Perception on Didactic Lecture (DL) Case-Based Learning (CBL) in Percentage (\%) for Questions 1-8

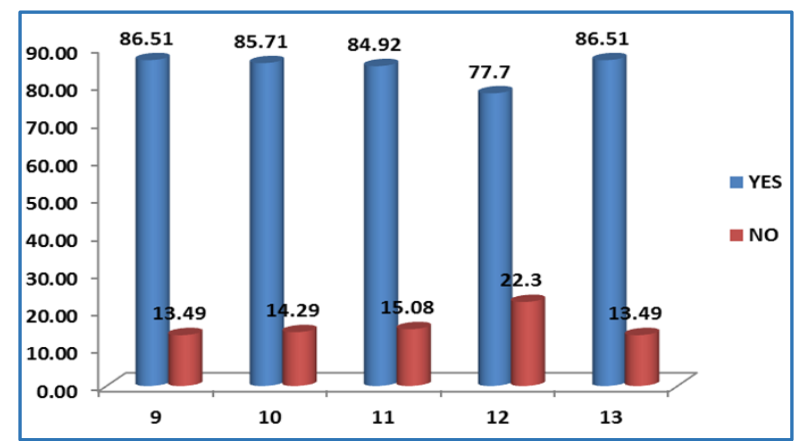

Fig. 2: Showing the Results of Students' Perception on Didactic Lecture (DL) Case-Based Learning (CBL) in Percentage (\%) for Questions 9-13

\section{DISCUSSION}

Meyer $\mathrm{C}$ et al, in their study stated that CBL proved to be an interesting concept and it helped the students in improving their academic performances, as it helped in developing interest about the subject, as all the students were curious and attentive and it also motivated them to actively participate with each one giving their inputs.[8]

According to Cliff WH et al and Srinivasan $\mathrm{M}$ et al studies showed CBL made the subject easier to learn and it also solidified their understanding of the subject. It helped them in developing logical thinking, clinical reasoning and diagnostic interpretation. This was also observed by other previous workers. $[9,10]$

CBL session in Biochemistry is a guided enquiry method, in which students face case scenario. The students have to think, define, struggle with problem and try to resolve it.[11]

This process enhances students' ability to synthesize, evaluate and apply information and concepts.[12]

Other advantages of CBL are that it promote self-directed learning, improves decision making and problem solving attitude.[13]

Overall outcome of this process is that it allows students to undergo meaningful learning. Meaningful learning involves acquisition of knowledge that can be stored and accessed from many different starting points. Also, students have to integrate well with other knowledge areas.[14]

Our results also supported the above studies, which showed CBL as useful in understanding Biochemistry topics 
and to fill the learning gaps. The students were able to critically think and build the concepts very well at the end of CBL session compared to didactic lectures.

Our results were supported by some of the other medical education researches, which stated that CBL could help in developing an effective learning environment with the use of specific learning objects.[15-17]

In line with previous studies, our study also showed the CBL facilitated interaction between staff and students from different cultures and backgrounds, which helped them developing their inter- and intra-personal relations.

Faculty training is very important in the selection of the case that should reinforce the students' understanding of the key concepts and the mechanistic processes of Biochemistry.

Books are available, that have clinical cases, but much of this material does not appear to have been specifically written to reinforce the student's understanding of the subject. [3,18]

Formulating cases appropriately and stating specific learning outcomes is challenging and crucial at first year stage because, first year students are not fully aware of pathology and medicine aspects of a clinical case. Hence all the aspects of a clinical case cannot be discussed at this level.

At RAKCOMS we have Center for educational development and research (CEDAR) which trains the faculty for this exercise.

The use of case studies in the basic sciences has shown a positive effect on the learning outcomes.[14,19-21]

Our results also supported the above studies; around (85\%) felt cases used during CBL were interesting and relevant to first year.

\begin{tabular}{|c|c|}
\hline Didactic Lecture (DL) & Case-Based Learning (CBL) \\
\hline Structure and function of cell and cellular organelles & Aminoacid and protein structure \\
\hline Structure of carbohydrates and lipids & Isoenzymes and diagnostically important enzymes \\
\hline Enzyme classification, specificity, kinetics, inhibitors and regulation & Inhibitors of biological oxidation \\
\hline Electron transport chain/oxidative phosphorylation & HMP shunt \\
\hline $\begin{array}{l}\text { Glycolysis, tricarboxylic acid cycle, gluconeogenesis and glycogen } \\
\text { metabolism }\end{array}$ & Blood glucose regulation \\
\hline Metabolism in muscle during exercise and rest. & Heme synthesis and disorders \\
\hline Vit D metabolism & Iron, Vit B12 and folic acid metabolism \\
\hline Digestion and absorption of carbohydrates, lipids and proteins & Plasma proteins and immunoglobulins \\
\hline Energy metabolism & $\begin{array}{l}\text { Assessment of nutritional status and disorders of } \\
\text { nutrition }\end{array}$ \\
\hline Fatty acid oxidation and cholesterol metabolism & Liver metabolism \\
\hline Acid base, buffer and regulation of $\mathrm{pH}$ & Ketone body metabolism \\
\hline Amino acid catabolism and urea cycle & Lipoprotein metabolism \\
\hline $\begin{array}{l}\text { Purine, pyrimidine metabolism and structure of DNA with organisation } \\
\text { and types and structure of RNA. }\end{array}$ & Disorders of acid base balance \\
\hline DNA replication, repair, gene regulation and molecular techniques & Urea cycle disorders and renal function tests \\
\hline Mechanism of hormone action and regulation & $\begin{array}{l}\text { Glycine metabolism, Inborn errors of aromatic and } \\
\text { branched chain amino acids. }\end{array}$ \\
\hline Neurotransmitters and neuronal metabolism & $\begin{array}{l}\text { Genetic code and mutation, transcription, translation, } \\
\text { cancer biology }\end{array}$ \\
\hline & Adrenal and thyroid hormones and disorders \\
\hline \multicolumn{2}{|c|}{ Table 2: Topics Covered by Didactic Lecture and CBL } \\
\hline
\end{tabular}

\section{Appendix-1 Example of a Case Scenario for CBL (HMP SHUNT)}

A 12-year-old African-American female presents to the emergency room with complaints of bilateral thigh and hip pain. She reports having similar pain episodes in the past, sometimes requiring hospitalization. On examination, she has no fever. Her conjunctiva and mucosal membranes are slightly pale in coloration. She has nonspecific bilateral anterior thigh pain with no abnormalities appreciated. The remainder of her examination is completely normal. Laboratory investigation revealed her haemoglobin $(\mathrm{Hb})$ level is low at $6.9 \mathrm{~g} / \mathrm{dL}$.

1. Based on the above case what is the case? Justify your finding.

2. What is the biochemical mechanism in above case?

3. What is the biochemical basis for her symptoms?

4. Explain the primary, secondary, tertiary and quaternary levels of protein structure giving haemoglobin as example.

5. Name the bonds stabilizing different structural organization of protein.

6. Give the examples for the different levels of structural organization with disorders related to it.

\section{CONCLUSION}

We conclude that understanding the concepts of Biochemistry topics, in an interesting and enjoyable way, case-based learning proved more effective than didactic lecture method. This method is also a good tool to promote active independent learning, student reasoning and inter and intra personal relations.

Didactic lectures have an important place in the classroom; this should never constitute the sole teaching technique in a course or even perhaps the dominant one.

CBL should be used as a routine method at appropriate places in teaching the subject of Biochemistry along with other methods like didactic lecturing, problem-solving sessions, Team based learning, and other small-group activities. By doing this we can create less stressful environments among students to learn meaningfully and make them globally competent medical professionals to meet the challenges of $21^{\text {st }}$ century.

\section{ACKNOWLEDGEMENT}

My sincere thanks to all the students of first year MBBS, batch of RAK College of Medical Sciences, RAKMHSU, for their 
cooperation and support throughout the study. We are thankful to Prof. Kannan, Dean of RAKCOMS for his continuous support and motivation for conducting this study. We are also thankful to Mrs. Sheela M.Sc., for her assistance in conducting of this study.

\section{REFERENCES}

1. West DC, Pomerory JR, Park JK, et al. Critical thinking in graduate medical education: a role of concept mapping assessment? JAMA 2000;284(9):1105-10.

2. Rendas $A B$, Fonsec M, Pinto PR. Toward meaningful learning in undergraduate medical education using concept maps in a PBL pathophysiology course. Advan Physiol Edu 2006;30:23-9.

3. Michael J. In pursuit of meaningful learning. Advan in Physiol Edu 2001;25(3):145-58.

4. Herreid CF. Case studies in science- a novel method of science education. J Coll Sci Teach 1994;23:221-9.

5. Norman GR, Schmidt HG. Effectiveness of problem-based learning curricula: theory, practice and paper darts. Medical Education 2000;34(9):721-8.

6. Burrowes PA. A student-centered approach to teaching general biology that really works: lord's constructivist model put to a test. Am Biol Teach 2003;65(7):491-502.

7. Lundeberg M, Yadav A. Assessment of case study teaching: where do we go from here? part 1. J Coll Sci Teach 2006;35:10-13.

8. Meyer C, Jones TB. Promoting active learning: strategies for the college classroom. Jossey-Bass 1993:103-19.

9. Cliff WH, Wright AW. Directed case study method for teaching human anatomy and physiology. Advances in Physical Education 1996;270(6 Pt 3):S19-28.

10. Srinivasan M, Wilkes M, Stevenson F, et al. Comparing problem based learning with case-based learning: effects of a major curricular shift at two institutions. Acad Med 2007;82(1):74-82.

11. Setia S, Bobby Z, Ananthanarayanan P, et al. Case-based learning versus problem based learning: a direct comparison from first year medical student's perspective. Webmed Central medical education 2011;2(6):WMC001976.
12. Kamat SK, Marathe PA, Patel TC, et al. Introduction of case-based teaching to impart rational pharmacotherapy skills in undergraduate medical students. Indian Journal of Pharmacology 2012;44(5):634-8.

13. Thistlthwaite EJ, Davies D, Ekeocha S, et al. The effectiveness of case-based learning in health professional education a BEME systematic review: BEME guide no 23. Med Teach 2012;34(6):e421-44.

14. Schoeman JP, Schoor VM, van der Merwe LL, et al. A casebased small group cooperative learning course in pre clinical veterinary science aimed at bridging basic science and clinical literacy. JS Afr Vet Assoc 2009;80(1):31-6.

15. Burrowers PA. A student-centered approach to teaching general biology that really works lord's constructivist model put to a test. Am Biol Teach 2003;65:491-502.

16. Surapaneni KM. The effect of integrated teaching with case-based learning in the biochemistry of undergraduate medical curriculum. Journal of Clinical and Diagnostic Research 2010;5:3058-60.

17. Reicks M, Stoebner T, Hassel C. Evaluation of a decision case approach to food biotechnology education at the secondary level. J Nutr Educ 2003;28:33-8.

18. McRae MP. Using clinical case studies to teach biochemistry in a doctoral program: a descriptive paper. Creative Education 2012;3(7):1173-6.

19. Popil I. Promotion of critical thinking by using case studies as teaching method. Nurse Education Today 2011;31(2):204-7.

20. Groves M. Problem based learning and learning approach: is there a relationship? Adv Health Sci Edu 2005;10(4):315-26.

21. Sarmishtha G. Combination of didactic lectures and case oriented problem solving tutorials toward better learning: perceptions of students from a conventional medical curriculum. Adv Physiol Educ 2007;31(2):193-7. 